\title{
IDENTIFICATION OF STABILITY LOBE DIAGRAM FOR MILLING USING VIBRATION ANALYSIS
}

\author{
Belwalkar N. S. ${ }^{1}$, Mohite S. S. ${ }^{2}$, Kashyapi G. V. ${ }^{3}$ \\ 1,3 PG Scholar, Dept. of Mech., GCE, Karad, Maharashtra 415124, India \\ 2 Dept.of Mech., GCE, Karad, Maharashtra 415124, India \\ Email: 1belwalkarnachiket@gmail.com
}

\begin{abstract}
-
Chatter is a self-excited vibrations. Increased working speeds of machining produces excitation of oscillations and cause dynamic problems. Chatter reduces the tool life, produces poor surface finish, reduces productivity and increases rejections. The experiments performed in this experimental work describes the method for obtaining stability lobe diagram for milling operations and this to help operator in selecting combination of input cutting parameters, viz., depth of cut and spindle speed for chatter free machining. Vibration analysis technique is used for these experiments. Experiments are carried out on vertical milling machine and vibrations signals are acquired using accelerometer. AA-6061 material is used for workpiece. The results obtained shows that, vibration analysis is simple, easy and efficient method for obtaining stability lobe diagram which helps operator to select combination of input parameters, viz., spindle speed and depth of cut for chatter free maximum material removal rate.
\end{abstract}

Keyword: Self-excited, chatter, stability lobe diagram, material removal rate, accelerometer

\section{INTRODUCTION}

Milling operations entail different types of vibrations that can damage the machine tool and hinder the process. Among these, chatter is the most harmful. Chatter is a self-excited vibration that can occur during machining operations and becomes a common limitation to productivity and part quality. This phenomenon has several negative effects such as poor surface quality, unacceptable inaccuracy, excessive noise and tool wear, machine tool damage, reduced material removal rate (MRR), and increased costs in terms of time, materials and energy. Therefore, it becomes imperative to monitor the process and identify the region of chatter in terms of admissible cutting parameters.

Fig 1 (a) shows regenerative effect which amplifies the vibrations. Regenerative chatter is the most common form of self-excited vibrations. It can occur often because most operations involve overlapping cuts which can be a source of vibrations amplification. The cutter vibrations leave a wavy surface. When milling, the next tooth attacks this wavy surface and generates a new wavy surface. If there is a phase difference between these wavy surfaces as shown in figure 1 (b) then, these results in varying chip thickness and forces on the cutting tool.
This phenomenon can greatly amplify the vibrations, become dominant and built up chatter. Figure 1 (a) (i) shows, no phase difference between outer and inner surfaces of chip thus, there is no amplifications of vibrations. Figure 1 (b) (ii) shows, $90^{\circ}$ out of phase between outer and inner surfaces of chip. Figure 1 (b) (iii) shows, $180^{\circ}$ out of phase between outer and inner surfaces of chip which results in maximum amplifications of vibrations.
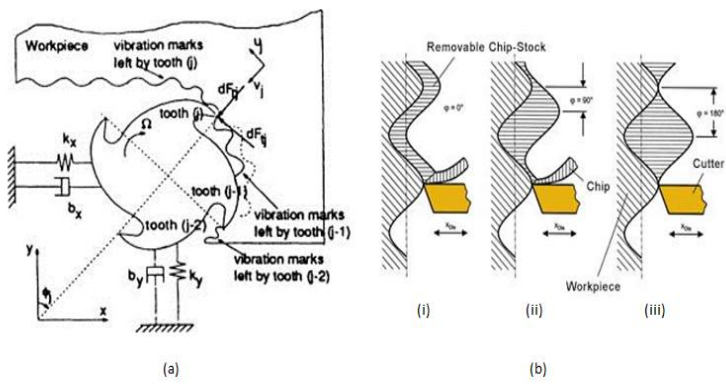

Figure 1 (a) Schematic diagram for regenerative effect, (b) Schematic diagram for variable chip thickness due to phase difference, courtesy G. Quintana [10]

There are two strategies to avoid chatter

1. Changing system's behavior

2. Using the lobbing effect 
Changing system's behavior method is based on improving the design of the machine tool to change its performance against vibrations or on the use of extra devices that can absorb extra energy or disrupt the regenerative effect. In second method, i.e., lobbing effect, machining parameters such as spindle speed, depth of cut are set such that chatter is avoided. These parameters are selected using stability lobe diagram (SLD). Figure 2 shows schematic figure of SLD. SLD is the graph of depth of cut verses spindle speed. SLD helps in selecting various combinations of machining parameters that results in maximum chatter-free MRR. In the next section, works of other authors related to this work are discussed

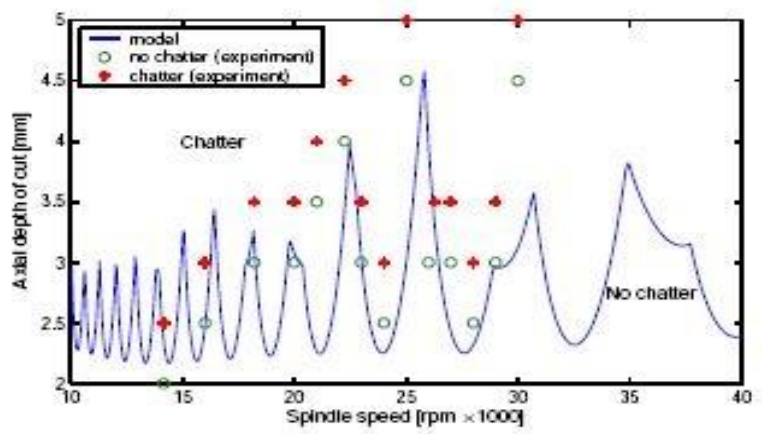

Figure 2 Schematic figure for SLD, courtesy G. Quintana [10]

\section{LITERATURE REVIEW}

Many researchers have made researches in the field of chatter. They presented various techniques including analytical as well as experimental to avoid chatter and select machining parameters, viz., depth of cut and spindle speed to achieve maximum chatter free MRR.

Aguiar et al. (2013) presented a correlation between surface roughness, tool wear and tool vibration in the milling process of hardened steel using long slender tools. They concluded that, wear was not the problem for the tools since, even after long cutting time (400 min), flank wear was very slight and surface roughness of the work-piece did not increased significantly with cutting time. They also concluded that, good workpiece surface roughness allied to long tool life of long slender tools can be achieved provided the tooth passing frequency used in the milling process (and its harmonics) does not produce high FRF values. Altintas et al. (1995) presented time varying dynamic force coefficients by approximating their fourier series components, and the chatter free axial depth of cuts and spindle speeds are calculated directly from the proposed set of linear analytic expressions without any digital iteration. The results showed that, the chatter free axial depth of cuts and spindle speeds are directly calculated using the proposed analytical but practical expressions. Quintana et al. (2008) proposed the methodology which was based on empirical tests where the workpiece permits a gradual increase of axial depth of cut in the feed direction, which represents the $Y$ coordinate of the SLD while the spindle speed (the Xcoordinate of the SLD) is increased between the passes. The cutting process is interrupted as soon as chatter is detected and the frontier between stable and unstable cutting, i.e., stability lobes diagram is identified. This provides a practical technique for optimal process planning of depth of cuts and spindle speeds in milling operations. This section has reviewed various types of chatter detection methods, viz., analytical, experimental using acoustic emission, accelerometer method, sound mapping techniques etc., in addition, existing methods for identification of chatter using accelerometers are intrusive, relatively expensive for widespread adaption or have low sensitivity. As a result, this work will focus on an experimental methodology of obtaining the SLD with the use of accelerometer efficiently. Addition to this, most of the experiments are conducted on high speed milling machine and very few experiments are conducted on low speed milling machine thus, this work is carried out on low speed milling machine. In the next section, methodology and equipments used for these experiments are presented.

\section{EXPERIMENTAL SETUP}

In this section, experimental setup for this experimental work is discussed. Experimental setup includes SIEMENS 828D CNC TRAINER MILLING MACHINE as shown in figure 4. Table 1 gives specifications of the machine used.

Table 1 Machine Specifications

\begin{tabular}{|c|c|}
\hline $\begin{array}{c}\text { Maximum speed of rotation } \\
\text { (rpm) }\end{array}$ & 2800 \\
\hline & 2000 \\
\hline $\begin{array}{c}\text { Maximum feed rate } \\
(\mathrm{mm} / \mathrm{min})\end{array}$ & \\
\hline
\end{tabular}


Accelerometer $608 \mathrm{M} 34$ is used for these experiments for acquiring vibrations signals. Tungsten carbide end mill cutter is used for slot milling operations. Natural frequency of tool is calculated as $560 \mathrm{~Hz}$. Table 2 below gives tool specifications.

Table 2 Tool specifications

\begin{tabular}{|l|c|}
\hline End mill tool material & Tungsten carbide \\
\hline Density $\left(\mathrm{g} / \mathrm{cm}^{3}\right)$ & 15.63 \\
\hline No. of flutes & 2 \\
\hline Diameter $(\mathrm{mm})$ & 8 \\
\hline Length of tool $(\mathrm{mm})$ & 109 \\
\hline
\end{tabular}

For these experimets, AA-6061 material is used for workpiece. Workpiece surface is inclined which allows gradually increase the depth of cut in feed direction, which represents the $y$-coordinate of the SLD, while the spindle speeds (the X-coordinate of the SLD) are increased between the passes. The cutting process is interrupted as soon as chatter is detected and the frontier between stable and unstable cutting, i.e., SLD is identified.

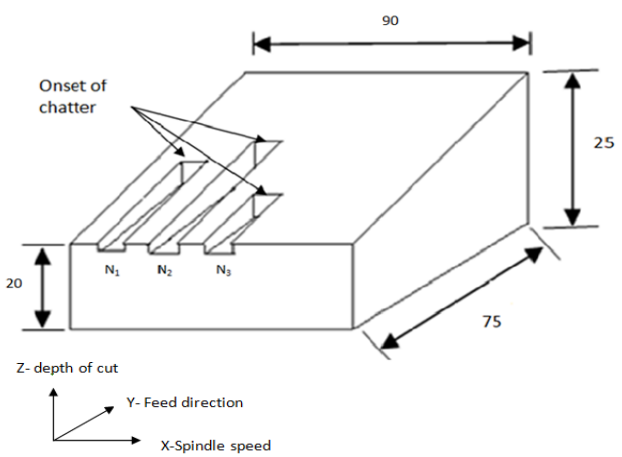

Figure 3 Tapered workpiece showing different passes with increasing rpm $(X)$ and onset of chatter $(Y)$

Figure 3 shows tapered workpiece showing different passes with increasing rpm (X-axis) and onset of chatter (Y-axis) used for these experiments. Spindle speeds on $X$-axis selected for these experiments are from $300 \mathrm{rpm}$ to $2500 \mathrm{rpm}$ with the interval of $200 \mathrm{rpm}$. Taper of $5 \mathrm{~mm}$ in $75 \mathrm{~mm}$ length is kept along Y-axis which helps in gradual increase in depth of cut in direction of feed. Feed of 0.1 $\mathrm{mm} / \mathrm{rev}$ is kept constant throughout all experiments. In the next section, the results of the experiments carried out in this work are presented and discussed.
The experiments are carried out on CNC milling machine. Tungsten carbide slender end mill cutter is used for slot milling on AA-6061 tapered workpiece. Accelerometer is used for acquiring vibration signals emitted during machining process. The results obtained are as shown in figure 4 .

Firstly, time domain spectrums are obtained for chatter detection. Figure 4 shows time domain spectrum and their FFT spectrums for $1000 \mathrm{rpm}$ spindle speed. Figure 4 (a) and (b) shows, time domain spectrum for stable and unstable conditions, respectively. Figure 4 (a) shows time domain spectrum for $1000 \mathrm{rpm}$ spindle speed and $0.6 \mathrm{~mm}$ depth of cut and fig. 4 (b) shows time domain for $1000 \mathrm{rpm}$ spindle speed and $0.8 \mathrm{~mm}$ depth of cut. Compairing these two graph shows, rise in amplitude for $0.8 \mathrm{~mm}$ depth as compared to $0.6 \mathrm{~mm}$ depth but, it is difficult to identify whether the rise in amplitude is due to chatter. So, these time domain signatures are converted to frequency domain. Figure 4 (c) and (d) shows frequency domain spectrums of figure 4 (a) and (b), respectively. In frequency domain, chatter can be identified clearly by observing amplitudes around natural frequency of the tool $(560 \mathrm{~Hz})$. Compairing these two frequency domain spectrums, it is clearly seen that there is sudden rise in amplitudes around $560 \mathrm{~Hz}$ frequency, which is natural frequency of tool used for these experiments. So, for better interpretation, frequency domain spectrums are used.
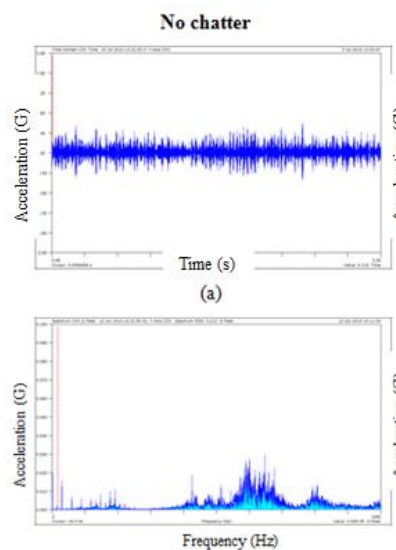

(c)

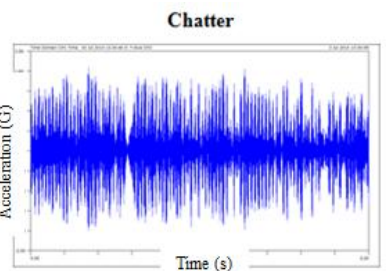

(b)

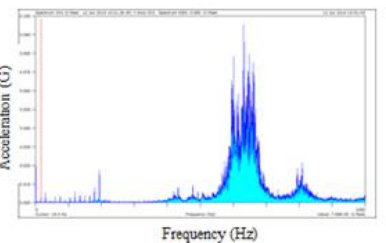

(d)
Figure 4 (a) Time domain spectrum for 1000 rpm spindle speed and $0.6 \mathrm{~mm}$ depth, (b) Time domain spectrum for $1000 \mathrm{rpm}$ spindle speed and $0.8 \mathrm{~mm}$ depth of cut, (c) FFT of fig. 4 (a) and (d) FFT of fig. 4 (b).

\section{RESULTS AND DISCUSSIONS}


Figure 5 below shows, comparison of two spectrums, one stable and other unstable condition for $1700 \mathrm{rpm}$ spindle speed.

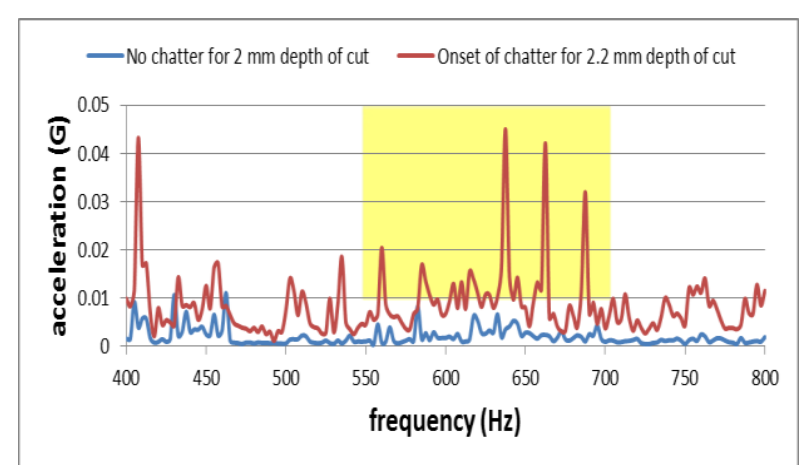

Figure 5 Comparison of frequency spectrums for with and without chatter at $1700 \mathrm{rpm}$

Table 3 maximim depths of cuts for AA-6061

\begin{tabular}{|c|c|}
\hline Spindle speeds (rpm) & Depth of cuts $(\mathbf{m m})$ \\
\hline 300 & 0.8 \\
\hline 500 & 0.8 \\
\hline 700 & 0.4 \\
\hline 900 & 0.4 \\
\hline 1100 & 0.8 \\
\hline 1300 & 0.8 \\
\hline 1500 & 2.4 \\
\hline 1700 & 2.2 \\
\hline 1900 & 0.6 \\
\hline 2100 & 0.8 \\
\hline 2300 & 0.6 \\
\hline 2500 & 0.6 \\
\hline
\end{tabular}

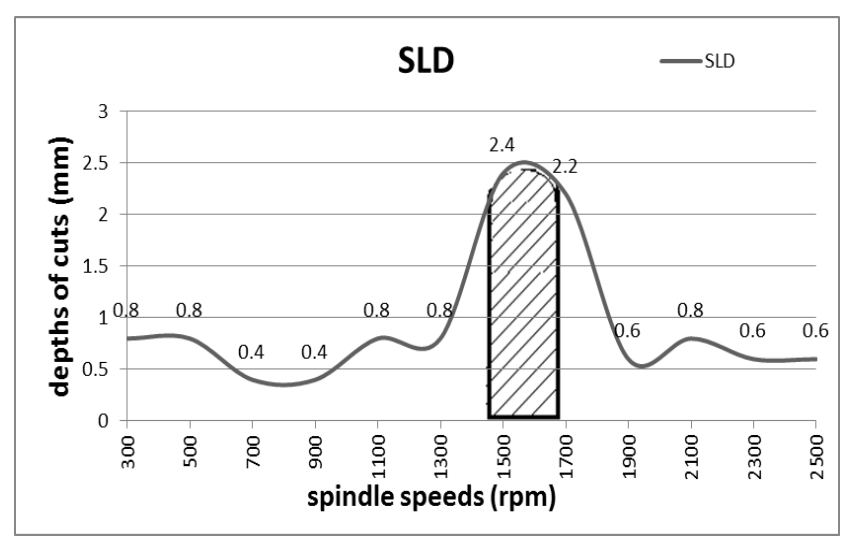

Figure 6 SLD for AA-6061, the region below the graph indicates chatter-free operation

Blue spectrum is for $1700 \mathrm{rpm}$ spindle speed and 2 $\mathrm{mm}$ depth of cut and shows stable cutting condition, i.e., no chatter whereas, red spectrum is for $1700 \mathrm{rpm}$ spindle speed and $2.2 \mathrm{~mm}$ depth of cut and shows unstable cutting condition, i.e., chatter. Sudden rise in amplitude of red spectrum between $550 \mathrm{~Hz}$ to $700 \mathrm{~Hz}$ as compared to blue spectrum clearly shows chatter. The highlighted region in graph helps in identifying chatter. If the acceleration values enter in this region then, it shows chatter for that particular spindle speed and depth of cut. In this case, acceleration values enter this region for 2.2 $\mathrm{mm}$ depth of cut. This clearly shows that, maximum 2.2 $\mathrm{mm}$ depth of cut is obtained for $1700 \mathrm{rpm}$ spindle speed without chatter. Similar graphs are obtained for remaining spindle speeds and depth of cuts for particular spindle speeds are obtained. Table 3 shows, maximum depth of cuts for respective spindle speeds.

Now, the SLD is plotted using this data. Figure 7 shows SLD for AA-6061 workpiece. The region below the graph indicates chatter free operation.

Figure 6 clearly shows, higher MRR is obtained at $1500 \mathrm{rpm}$ and $1700 \mathrm{rpm}$ spindle speeds which is highlighted with hatching. MRR calculated at $1500 \mathrm{rpm}$ and $2.4 \mathrm{~mm}$ depth of cut is $8.7 \mathrm{~cm}^{3} / \mathrm{min}$ and MRR calculated at $1700 \mathrm{rpm}$ spindle speed and $2.2 \mathrm{~mm}$ depth of cut is $8.9 \mathrm{~cm}^{3} / \mathrm{min}$. in the next section, conclusions and recommendations based on these results are presented.

\section{CONCLUSIONS}

In this experiment, SLD is plotted for AA-6061 workpiece for tungsten carbide end mill cutter with 109 $\mathrm{mm}$ length and $8 \mathrm{~mm}$ diameter. The method used for obtaining SLD is easy and simple method to identify chatter for particular machine tool and workpiece material. Following are the conclusions

Higher MRR is obtained between $1500 \mathrm{rpm}$ to 1700 rpm spindle speed. Maximum chatter free depth of cut of $2.4 \mathrm{~mm}$ is obtained at $1500 \mathrm{rpm}$ with MRR of $8.7 \mathrm{~cm}^{3} / \mathrm{min}$ but, maximum chatter free MRR of $8.9 \mathrm{~cm} 3 / \mathrm{min}$ is obtained at $1700 \mathrm{rpm}$ and $2.2 \mathrm{~mm}$ depth of cut.

This experiment is easy to carry out at any small scale or medium scale or large scale industries. By plotting SLD, an operator can select combination of cutting parameters, viz., spindle speed and depth of cut for chatter free machining which improves productivity, tool life, surface finish, avoid breakdown time, etc. 


\section{ACKNOWLEDGEMENT}

I sincerely thank to Government College of Engineering, Karad for providing equipments for the experiments and guiding me to carry out the experiments. I am deeply indebted to my guide Dr. S. S. Mohite, Professor and Head, Mechanical Engineering Department for guiding me for successful accomplishment of this experimental work.

\section{REFERENCES}

[1] Abele, E., Fiedler, U., 2004, Creating Stability Lobe Diagram during Milling, Institute of Production Management, Technology and Machine Tools, Germany.

[2] Aguiar, M., Diniz, A., Pederiva, R., 2013, Correlating surface roughness, tool wear and tool vibration in the milling process of hardened steel using long slender tools, International Journal of Machine Tools and Manufacture, 68, pp. 1-10.

[3] Altintas, Y., Budak, E., 1995, Analytical prediction of stability lobes in milling, CIRP Annals-Manufacturing Technology, 44, pp. 357-362.

[4] Chiou R., Liang S., 2000, Analysis of acoustic emission in chatter vibration with tool wear effect in turning, International Journal of Machine Tools \& Manufacture, 40, pp. 927-941.

[5] Dombovari Z., Iglesias A., Zatarain M., Insperger T., 2011, Prediction of multiple dominant chatter frequencies in milling processes, International Journal of Machine Tools \& Manufacture, 51, pp. 457-464.

[6] Lamraoui, M., Thomas, M. Badaoui, M., 2013, Cyclostationarity approach for monitoring chatter and tool wear in high speed milling, Mechanical Systems and Signal Processing.

[7] Marinescu I., Axinte D., 2008, A critical analysis of effectiveness of acoustic emission signals to detect tool and workpiece malfunctions in milling operations, International Journal of Machine Tools \& Manufacture, 48, pp. 1148-1160.

[8] Mousseigne, M., Landon, Y., Seguy, S., Dessein, G., Redonnet, J., 2013, Predicting the dynamic behavior of torus milling tools when climb milling using the stability lobes theory, International Journal of Machine Tools and Manufacture, 65, pp. 47-57.

[9] Quintana, G., Ciurana, J., Teixidor, D., 2008, A new experimental methodology for identification of stability lobes diagram in milling operations, International Journal of Machine Tools and Manufacture, 48, pp. 1667-1645.

[10] Quintana, G., Ciurana, J., 2011, Chatter in machining processes: A review, International Journal of Machine Tools and Manufacture, 51, pp. 363-376.

[11] Solis, E, Peres, C., Jimenez, J., Alique, J., Monje, J., 2004, A new analytical-experimental method for the identification of stability lobes in high-speed milling, International Journal off Machine Tools and Manufacture, 44, pp. 1591-1597.

[12] Totis, G., 2009, RCPM- A new method for robust chatter prediction in milling, International Journal of Machine Tools and Manufacture, 49, pp. 273-284. 